\title{
Dossier
}

Cine y Política en Chile

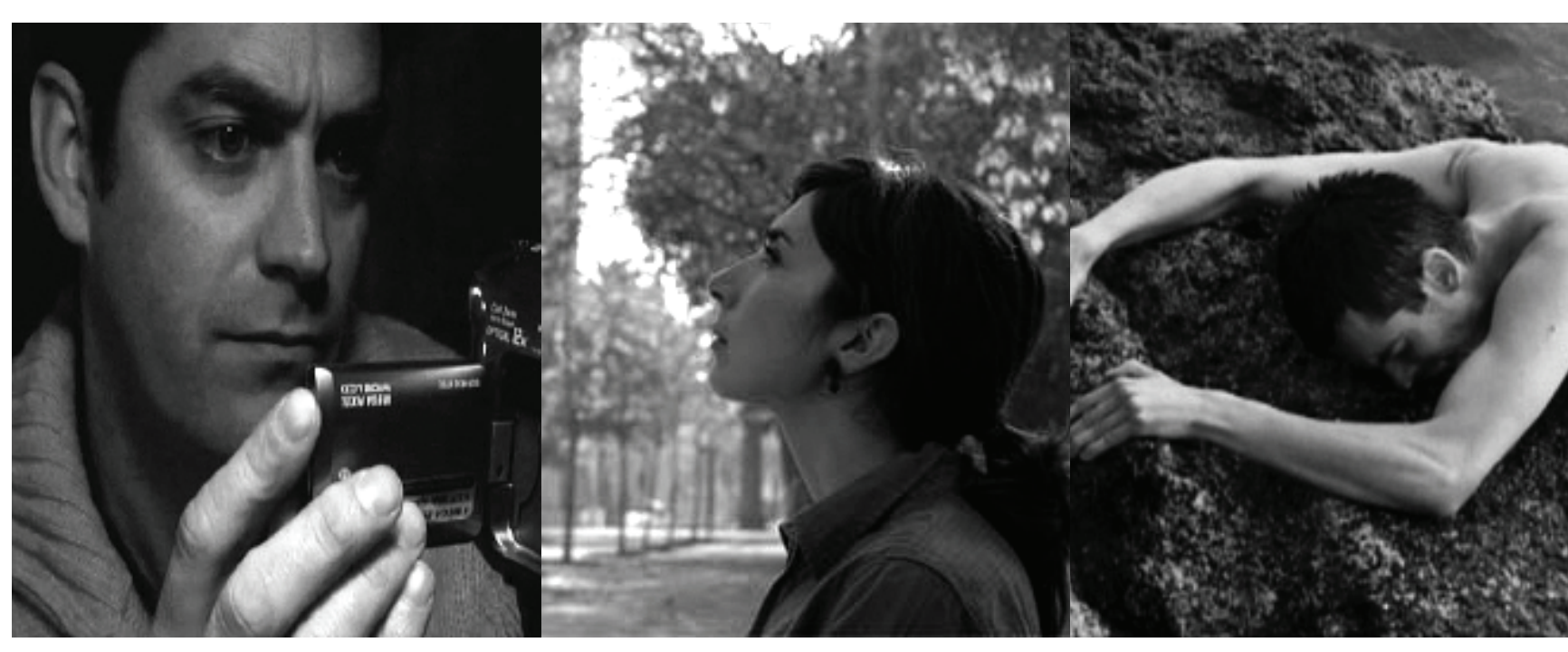




\section{Dolores políticos: reacciones cinematográficas. Resistencias melancólicas en el cine chileno contemporáneo}

Political Grieves: Cinematographic Reactions.

Melancholy Resistances in Chilean Contemporary Cinema

Antonella Estévez

Universidad de Chile

antonella.estevez@gmail.com

Resumen • Este texto se acerca a las relaciones entre cine y política desde los efectos que puede producir la segunda en las formas del primero. Desarrolla una mirada a cierto cine chileno contemporáneo y a las características formales que lo agrupan y propone que estas singularidades son una respuesta cinematográfica a las condiciones político-sociales que a los realizadores de estas películas les ha tocado vivir. Se desarrolla el concepto de "Melancolía Cinematográfica", y se da cuenta de los orígenes que tendría esa melancolía en el Chile actual. Sostenemos que a través de sus elecciones formales el cine puede acercarse a lo impresentable, y mediante la emergencia de los recursos de su construcción lograr atravesar la cáscara de lo superficial.

Palabras clave: Cine chileno contemporáneo, cine de postdictadura, duelo, efectos de la modernización, melancolía estética.

Abstract - The following text approaches the links between cinema and politics, considering the effects the second issue can produce upon the first. It develops an outlook on a certain type of Chilean contemporary films and the formal characteristics which gathers them, arguing that these singularities must be seen as a cinematographic response to the sociopolitical conditions the directors have experienced. The author displays the notion of "cinematographic melancholy", and the origins of this melancholy in the present day Chile. Through its formal decisions the cinema can get closer to what is unpresentable and by means of its resources, pierce the shell of superficiality.

Keywords: Chilean Contemporary Cinema, Post-Dictatorship Cinema, Mourning, Modernization Effects, Aesthetics Melancholy. 
Las relaciones entre cine y política, en el caso chileno, han tendido a estar definidas por lo narrado, más que por lo narrativo. Se habla del cine de la UP, del Nuevo Cine Chileno o, erróneamente, del cine de la transición como cine político poniendo el énfasis en el objeto del relato, más que en el relato mismo.

Partimos de la base -un poco obvia, pero a veces necesaria de explicitar- que todo cine es un ejercicio político. Toda obra de creación humana está desarrollada en un contexto social y cultural definido por lo político y proviene de creadores que -concientes de ello o no- poseen una mirada política respecto a la realidad que retratan o a la ficción que crean. Comprender las relaciones entre el cine y la política desde lo representado es una manera de hacerlo, pero este escrito propone acercarse desde la formalidad de la representación cinematográfica, tomando el devenir del sujeto político -que representa y es representadocomo la causa para el efecto que será la obra cinematográfica.

La década que termina es, en términos cuantitativos, la más productiva de nuestra historia. Más de 330 películas -entre largometrajes de ficción y documentales- fueron estrenadas entre el 2000 y el 2009, según registra el diccionario de cine chileno en Internet. En ese contexto hay un grupo de largometrajes de ficción que han llamado la atención por su rareza al interior del panorama cinematográfico de Chile. Son películas de bajo presupuesto, la mayoría de ellas óperas primas que, aunque no lograron masivo reconocimiento de parte del público (varias de ellas ni siquiera se estrenaron en salas comerciales), sí han logrado buena acogida en el circuito de festivales de cine, siendo ampliamente reconocidas por la crítica.

¿Qué tienen en común filmes como Play (Alicia Scherson, 2005), La Sagrada Familia (Sebastián Lelio, 2004), Y las vacas vuelan (Fernando Lavanderos, 2003), En la cama (Matías Bize, 2005), Oscuro/Iluminado (Miguel Ángel Vidaurre, 2008), El cielo, la tierra y la lluvia (José Luis Torres Leiva, 2008) y Rabia (Óscar Cárdenas, 2007)? Por un lado, son todos largometrajes que se han atrevido a desafiar los estándares da la narración naturalista -que ha primado en la producción nacional de los últimos veinte años- poniendo en el centro de su narración la reflexión respecto al lenguaje cinematográfico. Por otro, sus autores pertenecen a una generación de realizadores que comparten un entrenamiento formal en lo cinematográfico, además de una amplia cultura audiovisual y que, al mismo tiempo, tienen en común -la mayoría de ellos- haber nacido durante la dictadura militar en Chile y comenzar su trabajo profesional durante la transición democrática. En este texto propongo que es ese contexto político, social y cultural el que devendrá en melancolía cinematográfica, en un uso particular de las posibilidades del lenguaje cinematográfico. Por lo mismo, esta melancolía no se manifestaría tanto en los relatos escogidos, como en la manera en que estos toman forma cinematográficamente. No me referiré a películas que podrían considerarse melancólicas a nivel de argumento, como Se arrienda o Fuga, cintas que intentan -a mi parecer deficientemente- expresar el malestar existencial del sujeto a nivel del discurso verbal en los diálogos de los personajes, más que en la construcción visual de la película. Más bien, me enfocaré en cierto cine chileno que creo capaz de poner en obra un estado de ánimo que escapa a la representación directa, pero que es posible reconocer en la construcción formal de estas películas. Trabajamos entonces, bajo la premisa de que existiría en cierto cine chileno una tendencia a representar un estado de ánimo particular -la melancolía- utilizando un lenguaje cinematográfico que se aleja de los parámetros más clásicos de narración y que se acerca a la experimentación de las formas audiovisuales.

Este texto se detendrá primero en el proceso histórico que ha generado los dolores políticos de los que da cuenta su título y luego en como estos dolores se han expresado cinematográficamente mediante un ejercicio que podríamos denominar melancólico. Es con esta propuesta formal -cámaras en constante movimiento, una escala de planos más bien limitada y un uso del montaje que da espacio a otro tipo de experiencia del tiempo cinematográfico- que este grupo de cineastas conseguiría no solamente hacer práctica una reflexión acerca del propio lenguaje cinematográfico (haciendo evidente su construcción), sino que dar cuenta de lo impresentable: un estado post traumático, propio de una generación de jóvenes profesionales a los que les tocó crecer durante la dictadura militar en Chile y que hoy se desenvuelven en un país enfocado en el desarrollo económico, en donde el sujeto y sus espacios de intimidad (pareja, familia, hogar) están en constante crisis.

\section{EL CHILE MELANCÓLICO}

Durante todo el siglo XX el sueño de la modernización fue una constante en los gobiernos chilenos. La idea de llegar a alcanzar el desarrollo de un país del primer mundo, de lograr situarse en el mercado global y de extender a la comunidad nacional los beneficios de la modernidad fue parte del discurso común, que se repitió a lo largo de los distintos gobiernos pero con diversos matices.

En el contexto de la Guerra Fría en donde la opción socialista de Chile se leyó como un peligro para la estabilidad de la región -y para la tranquilidad del sector conservador nacional- la intervención militar se propone como una doble solución externa e interna: impedir que el "germen marxista" se siga propagando por América Latina y aprovechar la oportunidad para hacer los radicales cambios necesarios para que Chile se modernice.

La posibilidad de dejar una herencia económica sólida permitió a los militares, y a los grupos económicos que representaron, desarrollar un proceso de limpiado de imagen y situar la brutal violencia ejercida contra los adversarios y la suspensión de las libertades cívicas de la totalidad de la población como costos de este proceso de modernización.

Pamela Figueroa explica este proceso claramente señalando que la toma de medidas económicas de corte neoliberal funcionó también como una refundación de la sociedad chilena, alejando tanto por la fuerza militar como por los hechos y actuando sobre los cuerpos: "cambió la mentalidad y la forma de vida de los chilenos, al llevar a cabo una revolución modernizante" (2004: 4).

Lo que, para los límites de este escrito, nos interesa son esos cambios. Cambios poderosos en la subjetividad, en las maneras de ver y de relacionarse con el mundo, con un mundo en constante y brutal cambio. Un informe del Programa de las Naciones Unidas para el Desarrollo, publicado el año 2002, señala que durante este "camino al desarrollo" se ha transformado tanto el paisaje como la vida y la convivencia de los chilenos, volviéndose ambivalentes y confusas: "no es raro sentir desorientación y, a veces, impotencia. Ni sorprende cierta irritación en las relaciones sociales. Los chilenos viven con perplejidad este hallarse cada vez más cerca unos de otros (por las telecomunicaciones), pero sintiéndose extraños entre sí” (2002:15). En su muy comentado libro Chile Actual: Anatomía de un Mito, Tomás Moulian señala que, junto con la euforia, el exitismo y la creatividad mercantil hay, en nuestro medio, una incomodidad frente al nuevo escenario que se expresa con silenciosa elocuencia bajo las formas de la depresión, la desesperanza, el fatalismo, la sensación de ahistoricidad de la historia que se hace presente en el Chile Actual (32). 
Hace algunos años nos impactamos ante las impresionantes cifras de enfermedades mentales, especialmente depresión, presentes en Santiago según la OMS en 1996 alcanzaba el $56 \%$ de la población adulta. Según algunos especialistas esto debía asumirse como uno de los tantos "costos de la modernidad". La precariedad del trabajo, la mala calidad de vida, la ausencia de tiempo de esparcimiento, y uno de los más importantes, la profunda sensación de aislamiento y vacío emocional, se presentan como los principales factores que causan cuadros de ansiedad severos (Ramos y Simonsen, 1999:16).

Nos encontramos entonces con esta especie de esquizofrenia social que Moulian describe como un evidente desfase entre el lenguaje glorificador y el subdesarrollo de los recursos y de la cultura. Nos decimos modernos pero vivimos la mezcla de una infraestructura pobre con un ingenuo provincianismo mental.

Frente a un panorama de constante inseguridad, en donde una experiencia real de felicidad se hace cada vez más esquiva, el individuo ve en el consumo -y en las múltiples promesas de satisfacción que éste ofrece- la única posibilidad no sólo de disfrute, sino de participación en el contexto social. Se valora el consumo como un espacio determinante en la definición identitaria del sujeto contemporáneo, con las numerosas consecuencias que esto significa: "Para que el consumo se instale masivamente de esta forma se hace necesaria la muerte de las motivaciones trascendentales, sean ellas la revolución, la emancipación humana o la fe religiosa que dicta códigos de vida" (Moulian,1998: 25).

Así, el sujeto de la contemporaneidad se enfrenta a la necesidad de llenar un vacío que no puede ser llenado, pero -al mismo tiempo- es seducido frente a la invitación constante del consumo con la promesa de pertenencia al sistema neoliberal. Este acto consumista ofrece a nuestro sujeto ilimitadas posibilidades evasivas y hedonistas presentes en el contexto urbano. Gilles Lipovesky en La era del vacío nos habla de un sujeto que ya no se angustia por el sinsentido, pero que, sin embargo, convive con esta ingrata sensación de vacío que lo torna melancólico e indiferente. La siguiente cita pareciera estar describiendo a cualquiera de los personajes de las películas seleccionadas:

La indiferencia no se identifica con la falta de motivación, se identifica con la escasez de motivación, con la 'anemia emocional' (Riesman), con la desestabilización de los comporta(notivacion, con la 'anemia enocional' (Riesman), con la desestabilizaion de los conportamientos y juicios convertidos en 'lotantes" como las fluctuaciones de la opinión pública. El hombre indiferente no se aferra a nada, no tiene certezas absolutas, nada le sorprende, y sus opiniones son susceptibles de modificaciones rápidas [...] El narcisismo ha abolido lo trágico y aparece como una forma inédita de apatía hecha de sensibilización epidérmica al mundo a la vez que de profunda indiferencia hacia él (44 y 52 ).

\section{EL IMPOSIBLE DUELO SE VUELVE MELANCOLÍA}

Postulamos en este escrito que el origen de esta melancolía chilena contemporánea se alimenta de dos fuentes. La primera tiene que ver con los elementos comunes al sujeto contemporáneo de cualquier gran ciudad en desarrollo. A este sinsentido se le suma el duelo no asumido por el trauma de la dictadura. Crecer y desarrollarse en un país que ha vivido una experiencia política y social extrema y que ha escogido relacionarse con esa memoria desde el consenso político y la no emotividad, podría producir en nuestro sujeto un sentido de "deuda no saldada", de incomodidad frente a un pasado cuya violencia se niega, generando una angustia solapada que se manifestaría en melancolía.
Carlos Ruiz explica en su texto Democracia, consenso y memoria: una reflexión sobre la experiencia chilena que el proceso de reconocimiento de los atropellos a los derechos humanos y las muertes causadas por la dictadura fue imposibilitado por las condiciones impuestas por el mismo régimen militar para entregar el poder y la creación de una democracia de consensos - en donde quedan fuera de cuestión las posibilidades reales de verdad y justicia- limitada institucionalmente: "configura un escenario particularmente poco propicio y probablemente hostil hacia un trabajo de elaboración de la memoria sobre estos crímenes que se exprese con fuerza y pregnancia en el espacio público"(2006: 19).

La imposibilidad de realizar un duelo frente a crímenes que han afectado a tantos chilenos de manera personal y a toda la nación de manera social e histórica tiene sus consecuencias. Según explica Tomás Moulian, el duelo es un rito social destinado a rescatar al doliente de la aflicción, de ese desapego del mundo y de las inhibiciones de las funciones del yo que esto conlleva. Sin duelo no hay posibilidad de sanación, pero en este caso la imposibilidad es todavía más brutal ya que, a pesar de no poder enfrentarse a este hecho de manera directa, sí hay conciencia de que la situación del Chile Actual se construye sobre los cadáveres de otros chilenos, a lo que se agrega que "en esta situación de duelo, la aflicción personal de los deudos se mezcla con la pérdida general de un proyecto histórico, en un país contaminado y paralizado por la ideologización del asesinato político y la impunidad que rodea los actos de violencia y terror"(2006: 19).

Para Brett Levinson estos antecedentes han hecho que los habitantes del "Chile Actual" compartan una falta de explicación apropiada para la singularidad de sus pasados particulares; compartiríamos, entonces, lo inexplicable. Es tan brutal esta imposibilidad de cierre que incluso en los espacios destinados para ello, se han escatimado valores tan básicos como la posibilidad de conocer la verdad y de recibir justicia: "La situación no es en realidad un asunto de 'intercambiar' verdad por justicia; es una cuestión de hacer pasar la verdad por justicia. La verdad simula justicia: la justicia se mercadea mediante la verdad" (2001: 50). En ese mismo sentido Nelly Richard escribe:

El libreto oficial del gobierno de la Concertación ha convertido la memoria en una doble cita, respetuosa casi indolora. Tribunales, comisiones, monumentos a los derechos humanos citan regularmente a la memoria (hacen mención de ella, la notifican), pero dejando fuera de sus hablas diligentes toda la materia herida del recuerdo: densidad psíquica, volumen experiencial, huella afectiva, trasfondos cicatriciales de algo inolvidable que se resiste a plegarse tan sumisamente a la forma meramente cumplidora del trámite judicial o de la placa institucional (1998: 31)

A partir de diversas lecturas que se han hecho de los escritos de Freud se pone en evidencia que cuando no es posible realizar el duelo de manera correcta -esto es, instalando el objeto de duelo fuera del sujeto, nombrándolo y dándole un espacio para el recuerdo- la pérdida se hace aún más poderosa corroyendo silenciosamente todo el habitar del deudo. En palabras de Martine Déotte: "cuando se les prohíbe a los vivos enterrar a sus muertos negándoles sus cuerpos o sus últimos relatos, pareciera que el espacio público y político, el pasado, la filiación, la sobrevivencia misma se encuentran desvastados para siempre" (2006: 19).

$\mathrm{Al}$ no poder enfrentarnos a los muertos, estos se vuelven fantasmas y por lo tanto adquieren un poder y una movilidad mayor, instalándose en todos los rincones de nuestro habitar. Brett Levinson hace por nosotros una interesante lectura posible de la teoría de Freud aplicada al caso chileno: 
El terror no llega a ser terrible hasta que su inconmensurabilidad sale a la superficie. Este aspecto de la tesis sobre el terror asume un rostro importante en el contexto de la "transición" chilena, especialmente al situarlo al lado de la meditación freudiana sobre la melancolía. Freud argumenta que el duelo, el cual "entierra" al muerto y coloca el pasado en el pasado -permitiendo transición y salud- transcurre cuando la pérdida del objeto amado es de alguna manera rememorada, representada y medida. La representación como "re-presencia" o sustitución, atestigua la ausencia, el "ser-pasado" de la misma "cosa muerta". A la inversa, a melancolía se posiciona cuando la no-equivalencia o no-representación del objeto muerto nunca se materializa. El objeto muerto toma la forma del horror porque sale a la superficie como el muerto-viviente que rehúsa escabullirse, o llegar a ser historia; el ser amado mantiene su presencia en un presente al que ya no pertenece. Para Freud, pues, el pasado disminuye "firmemente", encabezando la transición, no cuando éste es olvidado sino cuando es recordado y valorado (2001: 48).

A esta imposibilidad de cierre respecto al momento más doloroso de nuestra historia contemporánea se suma, entonces, el proceso de modernización chilena. La presión por el desarrollo económico es un factor común y muy real para la generación de profesionales jóvenes de la primera década del siglo XXI, grupo del que provienen los autores de las cintas que analizaremos. Los gobiernos de la Concertación han puesto en su discurso un especial énfasis respecto a la macroeconomía del país, sin considerar que la realidad del trabajo en Chile -profesional o no- posee altos índices de precariedad, lo que determina las expectativas de futuro y el presente de muchos chilenos. A estos dos factores, que este ensayo sitúa como fuente de la melancolía chilena contemporánea, se podrían agregar también ciertas características propias de la idiosincrasia nacional ${ }^{1}$, en las que no nos detendremos por escaparse a las limitaciones de este escrito.

Roger Bartra plantea que la sobrevivencia del canon melancólico está garantizada por la función social, política y cultural de la melancolía en contextos históricos precisos. Para el autor, la estructura del mito melancólico es similar, pero son sus funciones las que son adoptadas y adaptadas según la sociedad del momento lo requiere para cumplir determinadas tareas que son funcionales del desarrollo de esa sociedad:

Lo que vuelve fascinante el caso de la melancolía es su doble condición: además de contener la estructura simbólica de un mito, se refiere también a las consecuencias trágicas de la soledad, la incomunicación y la angustia, ocasionadas por la siempre renovada diversificación de las experiencias humanas. La melancolía se convierte en una red mediadora que comunica entre sí a seres que sufren o intentan comprender la soledad y el aislamiento, la incomprensión y la dislocación, la transición y la separación. Así podemos suponer que quienes participan del canon de la melancolía se entienden y se desentienden, se comunican en la soledad y codifican el misterio de la separación (2001: 229).

A esta situación histórica podríamos sumar, en el caso chileno, ciertas características idiosincrásicas que han colía como parte centra que se vio agudizado por el duelo a partir de la pérdida de sus tierras y la violencia de la "colonización". Se añadiría a este elemento el aporte español que, específicamente durante la época imperialista, significó un mayor presencia de las enfermedades del alma en las expresiones sociales y artísticas. Un nuevo elemento podemos encontrar en los textos donde Benjamín Subercaseaux relacionaba el clima y la geografía chilen con la psicología local, señalando que corresponde a un tipo psicologico depresivo producto de su relación con su contexto físico (1939. p. 72).

\section{LA MELANCOLÍA APARECE EN LO INNOMBRABLE}

Expuesto nuestro escenario, en este punto podemos comenzar a discutir respecto al rol del arte en este proceso. En un momento histórico donde en Chile no es posible hablar de los costos humanos y sociales que ha tenido la modernidad "disfrutamos" el rol del arte y su capacidad de visibilizar aquello que escapa del discurso político que ha estado presente en una serie de reflexiones críticas desarrolladas en los últimos años.

Comentando el texto Postdicadura y reforma del pensamiento de Alberto Moreiras, Nelly Richard señala que el pensamiento de la postdictadura es "más sufriente que celebratorio", ya que -como señalaba más arriba- está dolorosamente condicionado por los afectos-efectos de la pérdida de objeto que marcan el duelo. Para Moreiras este pensamiento habría transitado en dos sentidos que pudiesen parecer contradictorios: primero con esperanza desde la violencia militar hacia la recuperación democrática pero, además desesperanzado desde el fervor militante de los grandiosos ideales revolucionarios y de las solemnes convicciones históricas hacia el escepticismo del valor que hoy cultiva el indiferente relativismo del mercado neoliberal:

Es un pensamiento que experimenta, entonces, la tristeza de la desposesión y del fracaso al ver como se alejan, difusos, y luego naufragan en un tiempo ya irrecuperable, el motivo utópico y la pasión existencial que justificaban las luchas ideológicas del pasado. Al desvanecerse el sentido que les daba fuerza e intensidad a las luchas de la subjetividad y una biografía intelectual contestataria cunde la melancolía como estado aflictivo de irresolución del duelo[...] las figuras del trauma, del duelo y de la melancolía pasaron a ser las figuras emblemáticas de cierto pensamiento crítico de la postdictadura, en tanto figuras que connotan la sensación de irreconocimiento y desamparo que afecta al sujeto del quiebre histórico cuando ese sujeto ya no cuenta con nombres y conceptos suficientemente fiables para verbalizar su experiencia, la radicalidad catastrófica de su devastada experiencia ${ }^{2}$ (2001: 131).

En la ponencia titulada Inmediatez y Frontera -presentada en el coloquio "Arte y Política” del 2003-Carlos Ossa señala que en el contexto de la transición el arte no logra escapar de los límites impuestos por la situación que lo contextualiza y que una política distanciada de su deseo va dejando en el arte una huella melancólica: “donde la represen-

Richard, Nelly Las marcas del destrozo y su reconjugación en plural en "Pensar en /la postdictadura" Nelly Richard y Alberto Moreiras, editores. Santiago: Cuarto Propio, 2001. p.48 Ana del Sarto aporta en este melly texto un ensayo en donde señala que incluso el pensamiento crítico ha resultado víctima de la melancolía a ponerla -junto a la pérdida- como el núcleo a través del cual el 'pensamiento crítico' puede postularse como anti-proyecto: la pérdida no puede ser nombrada, porque de serlo, el proyecto se desvanecería como tal; la melancolía, en tanto, señala que el proyecto es precisamente esta eterna 'tarea', este constante juego intelectual que retrabaja su síntoma, para de esa manera, retroalimentarse en el estado melancólico: "Es precisamente el carácter fantasmático de la melancolía o, dicho en otros términos, el evitar nombrar o referir la pérdida, negándola, lo que permitiría a estos discursos implementar una cura analítica: estrategia del 'duelo del duelo'. Sin embargo, al negar la negación de la pérdida, materializan una nueva paradoja: en vez de alcanzar la suprema alegria, concluyendo asi el proceso de duelo, se sumergen cada vez mas en la melancolía. Mediante esta redoblada melancolización, estos discursos sobre el duelo sólo encuentran referentes fantasmáticos a más la melancolía emergente del proceso de duelo inconcluso" 
tación de lo social jamás logra constituirse, sólo insinúa, desmiente y cela el tacto de un espesor cansado, de una historia irregular y de poderes que manipulan discursos para esconder el deterioro del signo que gobierna"(159).

Como se señalaba anteriormente, el silencio frente a los crímenes cometidos en dictadura era condición tanto para el retorno de un sistema democrático como para la implementación del sistema de libre mercado, lo interesante es que, siendo la existencia de la pérdida real, ésta sigue apareciendo aunque se niegue a nombrarla. Aparece entonces sin nombre, deslizándose entre las construcciones discursivas que artificialmente se han levantado para ocultarla.

En su texto "Alegorías de la derrota: la ficción postdictatorial y el trabajo de duelo", Idelber Avelar señala que a pesar de que el mercado exige el reemplazo de lo viejo por lo nuevo, y la relegación del pasado al pasado, existe un resto que permanece y que impide que el duelo se integre también a la lógica de mercado. Este resto es de lo que se hace cargo el arte -en el análisis de Avelar, la literatura; en el nuestro, el cine- trayendo de vuelta aquello a lo que se le quiere dar la espalda:

En el mismo mercado que somete el pasado a la inmediatez del presente, la literatura doliente buscará esos fragmentos y ruinas -rastros de la operación sustitutiva del mercado- que pueden activar la irrupción intempestiva del pasado en el presente a la actualidad su fundamento, su anclaje en lo inactual (286).

Lo llamativo de este proceso es que al negarse -desde la política- la posibilidad de desarrollar un duelo, de enfrentarse al pasado, de nombrar el horror con el propósito de que el pasado no interfiera en el presente, se consigue exactamente lo contrario. Lo concreto de la violencia se transforma en un espacio fantasmal, móvil, al que es imposible aplacar. Se cuela por los ranuras de las paredes que la transición construyó para dejarlo atrás y se hace presente, silenciosa, pero poderosamente en los espacios de la representación que siguen sin poder darle nombre, pero que ya dan cuenta de él.

Siguiendo con Avelar, nos enfrentamos ahora a la cuestión de cómo se narra aquello que no se puede nombrar. El problema, en este caso no está dado por las limitaciones impuestas por la censura o la lógica de mercado, sino por las dimensiones inconmensurables del horror, el dolor y la pérdida: "se trata de la trivialización del lenguaje y la estandarización de la vida, que vacían de antemano el poder didáctico del relato y lo sitúan en una aguda crisis epocal, derivada precisamente de ese divorcio entre la narrativa y la experiencia"(282). Sin embargo, también complica la posibilidad de enfrentarse al dolor de la pérdida la resistencia que tiene el propio duelo a concluir. Avelar señala que el duelo siempre y necesariamente se plantea a sí mismo como una tarea irrealizable.

Así serían -al mismo tiempo- el sujeto y su escritura los que han incorporado la pérdida. Han integrado la ausencia, volviéndose ellos mismos en parte ausentes, por lo que la posibilidad de narrar se vuelve también imposible y entonces volvemos, una vez más, a la melancolía:

La pérdida con la cual la escritura intenta lidiar ha tragado, melancólicamente, a la escritura misma: el sujeto doliente que escribe se da cuenta de que él es parte de lo que ha sido disuelto. Esta percepción tiene lugar en ese espacio gris en que el duelo bordea con la melancolía. La melancolía emerge así de una variedad específica del duelo, de aquel duelo que ha cerrado un círculo que incluye al propio sujeto enlutado como objeto de pérdida (316).
Jean Louis Deotté trabaja en el texto El arte en la época de la desaparición el concepto de "comunidad de la desaparición" que serían aquellos que han sido afectados de una u otra manera por el daño y el silencio, construyéndose entonces alrededor del vacío, de la pérdida del sentido histórico. Estos sujetos serían víctimas de la modernidad, habitándola desde el fracaso (2006: 19). Es este sentimiento lo que movilizaría las obras que, en este trabajo, considero melancólicas; no se trataría entonces de un estado de ánimo no transitorio, sino más bien permanente, que acompaña al sujeto contemporáneo. Sujeto que se desenvuelve en el contexto de un creciente bienestar económico, sujeto que pareciese tener sus problemas básicos de subsistencia más bien resueltos, pero que no sabe muy bien qué hacer consigo mismo, sujeto del duelo. Esta crisis interna del individuo se ve agudizada gracias a la inquietud del mundo que vive, en donde las grandes utopías se han desvanecido, y en donde las guerras y los conflictos sociales en vez de aminorar, crecen en complejidad y brutalidad.

\section{ANATOMÍA CINEMATOGRÁFICA DE LA MELANCOLÍA CONTEMPORÁNEA}

Rindiendo tributo al clásico escrito de Robert Burton, y con nuestro objeto de análisis ya instalado -en término de contexto-, en esta sección proponemos un perfil de las características centrales de la melancolía contemporánea y varias propuestas de cómo ésta sería capaz de representarse en el lenguaje cinematográfico. Partamos recordando que en este escrito se fundamenta en la convicción de que -a partir de las elecciones autorales de los cineastas- es posible dar cuenta de lo irrepresentable desde la construcción formal que estos autores realizan. Como señalaba al inicio, la melancolía es un estado que escapa de la representación directa pero a la que se puede apelar mediante el uso de recursos poéticos que estarán guiados por el interés y la sensibilidad del creador, de allí la relevancia de la experiencia y contexto del realizador.

El cine, mediante una utilización estratégica del lenguaje cinematográfico, puede acercar al espectador a este espacio anímico a través de una experiencia estética. Esto, porque a pesar de la impresión de realidad que acompaña el hacer cinematográfico es necesario estar consciente de que, como señala Julia Kristeva: "El cine no reproduce cosas: las manipula, las organiza, las estructura. Y los elementos toman sentido sólo cuando se logra una nueva estructura a partir del montaje de aquellos (1988: 321).

A través de sus elecciones formales, el cine puede acercarse a lo irrepresentable, y mediante la emergencia de los recursos de su construcción lograr atravesar la cáscara de lo superficial. El lenguaje cinematográfico se instala de esta manera como vehículo privilegiado de acercamiento a este estado de ánimo tan propio de nuestro tiempo, la posibilidad de dar cuenta de lo impresentable, de aquello que está en el alma no sólo de los personajes, sino del realizador y del público, creando una conexión que supera los límites de la materialidad de la obra, pero que se sustenta en ella. Es en los espacios de cotidianeidad -construida simbólicamente en el cine- en que nosotros, como espectadores, podemos percibir la presencia de aquello que no se puede representar, pero que logra dar cuenta de sí mismo a través de las posibilidades del lenguaje cinematográfico. Recordemos que según Mitry, la actitud del espectador de cine consiste en descifrar, a través de lo real percibido, las ideas sugeridas más que las significadas, dado que por necesidad las significaciones cinematográficas son imprecisas y ambiguas. Los sucesos referidos por la narración no constituyen más que 
el elemento primero de la película su nivel elemental de comprensión (2002: 470). Es en esta experiencia cinematográfica en que nosotros como espectadores podemos acceder a la melancolía, siendo alentados por la construcción de lo que vemos en pantalla: "El cine como documento puede 'recuperar la imagen' y procurarnos experiencias (y con ellas traer y levantar la memoria) en el seno de lo histórico de vuelta así de sus devaneos mortuorios" (Fernández, 2005: 141).

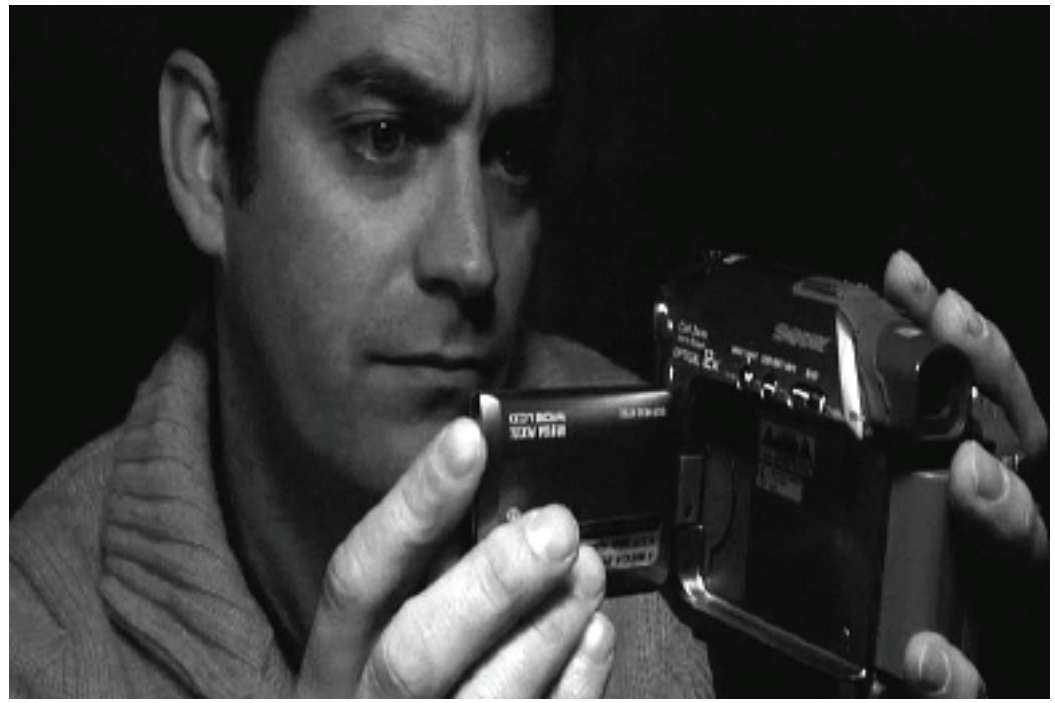

Felipe Braun. Oscuro/lluminado.

Como señalaba más arriba, la melancolía es un objeto escurridizo, difícil de asir en lo evidente y en donde las estrategias barrocas de representación parecen resultar eficaces. Regresamos entonces a la idea de la superficie, de la forma. Enfrentados al desafío -consciente o no- de instalar en pantalla un estado del alma que es confuso y de difícil acceso, es en la forma en donde se arma la historia, la forma como única manera de comunicar a espectador este estado que comparten. Recordemos que según Mitry: "para el espectador es la forma la que llama a la idea, dado que la forma es la única manifestación sensible de ésta” (455). Entonces, ¿Cómo debería ser esta forma para expresar la melancolía? Propongo algunas características de una traducibles en la otra para ir armando esta gramática cinematográfica de la melancolía.

Si coincidimos con Adrian Martin, en la atmósfera como aquello que junta se definen, se ponen en circulación y se transforman todos los elementos de la película: sus personajes, eventos, gestos, lugares, espacios, imágenes y sonidos (2008: 33). Diríamos, entonces, que lo primero sería reconocer la existencia de una "atmósfera melancólica". Ésta estaría definida -y definiría - tanto en la forma como en el fondo de la película. Señalaba en la introducción que las películas de mi interés no son aquellas que argumentalmente tienen la melancolía como centro de su problemática consciente, en donde los personajes se preguntan a viva voz por el sentido de su existencia y la búsqueda de significación, sino aquellas en que la melancolía se expresa en la construcción formal de su propuesta narrativa, se construye cinematográficamente. Propongo que un grupo de cineastas jóvenes chilenos han logrado dar cuenta de esta melancolía a través de una serie de películas que comparten ciertas características. Sin embargo, cabe preguntarse ¿por qué este grupo de películas y no otras? Al comparar filmes como Y las vacas vuelan y Play con sus contemporáneas Fuga, Secuestro o Gente decente, queda en evidencia la distancia de registro que existe entre unas $\mathrm{y}$ otras, porque este segundo grupo de cintas tiene un enfoque bastante menos intimista y una propuesta conceptual que las acerca más a los objetivos del cine comercial. Estas últimas películas no nos interesan, porque no percibimos en ellas un interés de dar cuenta de la realidad chilena, sino más bien, de contar historias que podrían suceder -y funcionar comercialmente, según esperan sus productores- en cualquier lugar del planeta. Tampoco hay, en este segundo grupo de filmes, un real interés por la experimentación con el lenguaje cinematográfico. La emergencia de los recursos formales, que tanto nos interesa en cintas como La sagrada familia y En la cama, es reemplazada en estas películas "high concept" (como ellas mismas se denominan) por un lenguaje cinematográfico más bien clásico, con pretendidas cercanías al cine hollywoodense. Entonces, lo primero que tendría en común este grupo de películas que caracterizo como melancólicas sería su propuesta argumental, su guión. Este guión trabajaría a partir de un grupo reducido de personajes (dos o tres en su mayoría) y de una anécdota que podríamos calificar de menor, en contraposición con la del cine de género como la épica, el cine histórico, el policial o el melodrama. Hay quienes han señalado que este tipo de cine se aleja de lo narrativo, por la ausencia de grandes quiebres en el guión o por lo mínimo de sus diálogos. Para contra argumentar me valgo de las palabras de Christian Metz defendiendo de similares críticas al cine de Godard (otro referente evidente del "Cine Melancólico"):

En un filme de Godard, siempre hay una historia. Que esté "rota" o sea insólita, en lugar de ser caricaturescamente lineal, no cambia en nada la cuestión, y Godard es uno de nuestros más fecundos guionistas (ello es cierto incluso si el guión, en su caso, nace en medio del rodaje y, en cierto modo, no es más que una consecuencia del filme). Excluir del cine moderno la dimensión guionística o rebajar su importancia es pensar que los únicos guiones son los de Aurenche y Bost (2002:223)

Son estas pequeñas historias las que dan pie a la "construcción melancólica”, más allá del clásico uso de los recursos cinematográficos para contar una historia, acá la historia se sustenta en su manera de ser contada. Al levantar la forma y evidenciar su construcción, estas películas hacen una reflexión de su propia materialidad y desafían al espectador. Al quitar de en medio los diálogos explicativos o dramáticos, este cine pone su confianza absoluta en las posibilidades narrativas de lo visual "La densidad significante de la palabra y del silencio producen un efecto violentamente alucinatorio en la medida en que pueden interiorizar procesos frente a los poderes mostrativos de la imagen" (Doménec, 2002: 287). La emergencia de los recursos formales pone en evidencia la construcción del discurso cinematográfico. Le recuerda al espectador "no lo olvide, esto que usted ve no es la vida misma, es una construcción subjetiva a partir de la cotidianeidad". Aquí encontraríamos aquello que Jean Mitry identifica, como la cualidad estética, definida por la distancia que separa lo representado de la representación, la distancia que separa la cosa original del sentido y de los valores que adquiere mediante la representación que se le da. "Esto es cuanto queremos decir cuando hablamos de fuerza creadora. La forma, por supuesto, no crea el objeto representado ni la historia que cuenta, no crea el contenido. Pero sí crea las significaciones y gracias a ello determina el sentido de ese 
contenido" (2002: 460). No hablamos entonces de pura forma, no caen estas películas en la perfomance o en el video arte no narrativo, aquí definitivamente hay historia, pero esas historias no son las que comúnmente han definido a los "héroes" de la gran pantalla, sino que están fuera de la gran épica, de la aventura externa, y adquieren su trascendencia mediante la forma, no a pesar de ella, por eso son fundamentalmente cinematográficas.

\section{EL TIEMPO}

Como señalaba más arriba, el uso del tiempo es una característica común y evidente de este grupo de películas. Hablamos de largos planos secuencias, de tomas extensas -en donde pareciera que no sucede mucho- de una construcción en donde el montaje parece perder dinamismo y en la que la duración de los actos de los personajes tiene más relación con "la experiencia de la vida misma" que con el ritmo cinematográfico clásico. Un elemento que me parece esencial de la descripción que hace Kristeva de la melancolía tiene que ver con la relación entre el melancólico y su tiempo. La autora parte de la idea, apoyada por muchos especialistas, de que la pérdida de la velocidad motriz, afectiva e ideatoria es característica del conjunto melancólico-depresivo. La lentitud verbal sería una expresión de lo anterior: "el inicio de la enunciación es despacioso, los silencios son largos y frecuentes, los ritmos disminuyen, las enunciaciones se hacen monótonas y las estructuras sintácticas se caracterizan repetidamente por supresiones no recuperables" (1991:34). Me parece muy interesante que esta descripción del uso del lenguaje del melancólico sea absolutamente adecuada también para dar cuenta del uso del lenguaje cinematográfico que caracteriza las películas propuestas.

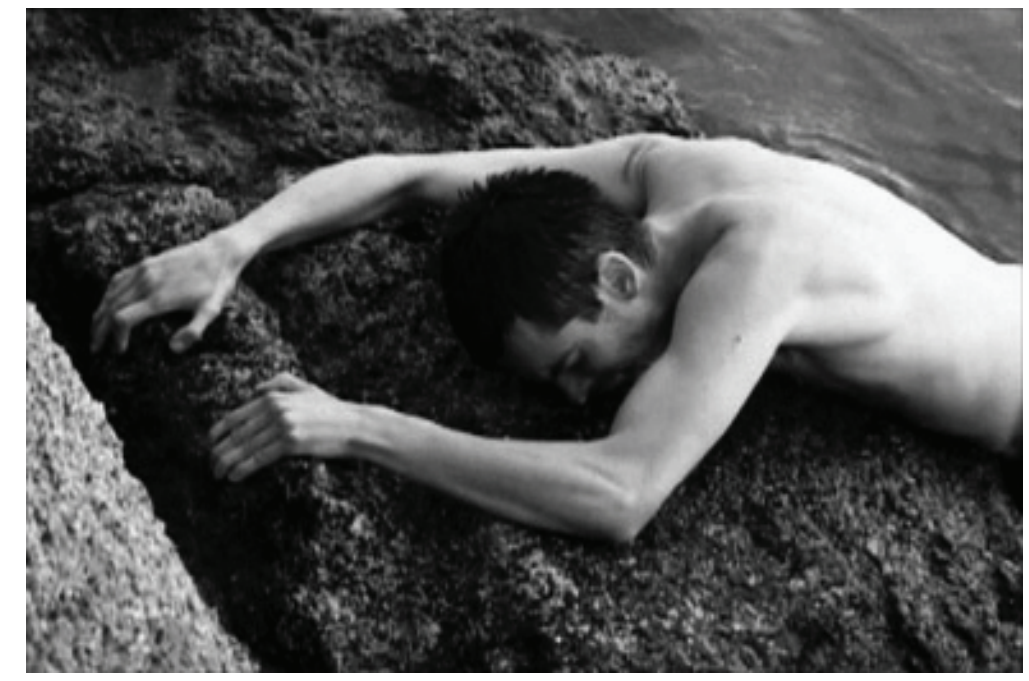

Sagrada Familia.
Las películas melancólicas le darían tiempo a sus personajes para desplazarse, pensar, sentir y también al espectador, que es obligado a detenerse en estas acciones cotidianas e impelido a experimentarlas bien, otorgándoles algún sentido o dejándose llevar por este devenir del tiempo cinematográfico armado desde el montaje tanto al interior del plano o durante la edición. Volvemos a Pasolini y sus argumentos respecto al uso del Plano Secuencia y sus posibilidades: El hipotético plano secuencia puro pone en evidencia por lo tanto, representándola, la insignificancia de la vida en cuanto vida. Pero a través de este hipotético plano secuencia puro, también logro saber -con la misma precisión de las pruebas de laboratorio- que la proposición fundamental expresada por lo más significante es: 'yo soy', o 'Hay' o simplemente 'ser'. Pero ¿es natural ser? No, no me lo parece; al contrario, me parece que es portentoso, misterioso y, en cualquier caso, absolutamente innatural (1971: 71).

Este tipo de preguntas son las que constantemente tiene el espectador al ser expuesto a este tipo de construcción, a la mirada cinematográficamente que se fija en la realidad y que deviene movimiento naturalista, monótono si se quiere, alejándolo de la ilusión dinámica de los saltos en el tiempo gracias al montaje. Según Mario Pezella al captar el momento del devenir del suceso, obligo a la consciencia a detenerse y a poner atención a cada una de las posibilidades de ese instante: "Haciéndose presentes y posibles las dimensiones que de otro modo serían incompatibles tanto en el tiempo como en la psique, la imagen se convierte en algo densamente simbólico. Su complejidad me interroga y me lleva a una inagotable meditación"(2004: 56). Así, aunque en apariencia muchas de estas tomas nos muestren momentos cotidianos insignificantes e irrelevantes, el potencial de significado presente en esa misma cotidianeidad es poderoso y puede permitir, al espectador sensible, abrir múltiples posibilidades de interpretación.

\section{DETENCIÓN EN LOS OBJETOS}

Una de las maneras más evidentes en que este devenir del tiempo melancólico se hace presente es a través de su detención en los objetos. Una idea recurrente en los textos revisados es que la relación entre el melancólico y los objetos es fundamental a la hora de definir la melancolía. El objeto de la melancolía es distinto al del duelo o al de la nostalgia. No se trataría de un objeto/sujeto/situación real del pasado del melancólico que éste ha perdido, sino más bien de un objeto/sujeto/situación idealizada por el melancólico que es inasible hoy, lo que no quiere decir que haya sido asible en el pasado o que lo pueda ser en el futuro.

Comentando los escritos clásicos de Sigmund Freud al respecto, Giorgo Agamben define el objeto de la intención melancólica como al mismo tiempo real e irreal, incorporado y perdido, afirmado y negado. De esta manera el deseo del melancólico es imposible, y quizás esté allí mismo la clave del goce de su melancolía:

La melancolía no sería tanto reacción regresiva ante la pérdida del objeto del amor, sino la capacidad fantasmática de hacer aparecer como perdido un objeto inapropiable. Si la libido se comporta como si hubiera ocurrido una pérdida, aunque no se haya perdido en realidad nada, es porque escenifica así una simulación en cuyo ámbito lo que no podía perderse porque nunca se había poseído aparece como perdido, y lo que no podía poseerse porque tal vez no había sido nunca real puede apropiarse en cuanto objeto perdido (2001: 53). 
Cinematográficamente uno de los recursos más utilizados para asir los objetos es el primer plano. Pezella nos lo explica, "Considerado superficialmente el primer plano se acerca bastante a un fragmento de realidad pura: pero cuanto más microscópicamente observemos un objeto o un rostro, más encontraremos materia descompuesta e indescifrable" (2004:57). Quizá por esto las películas melancólicas están llenas de planos fijos sobre objetos de lo más comunes. El lento derretir de una mantequilla en Play, una delicada toma en nadir de las hojas de los árboles en Navidad, las micros de Y las vacas vuelan, y así, innumerables tomas de objetos insignificantes, cotidianos que no están puestas allí para hacer avanzar la acción, no por lo menos en términos externos, sino para movilizar un razonamiento interior del sentido de los personajes, en la reflexión del espectador. Todo esto gracias a trabajo del fotógrafo, del realizador, que al detenerse en estos objetos propone una nueva valoración de las formas y de los contenidos. Según Jean Mitry este tipo de acercamiento visual saca a la luz las cualidades intrínsecas del objeto, lo traduce y permite revelar valores plásticos que el objeto tenía desde el principio, pero que son sólo develadas a través de este tipo de atención (2002: 460).

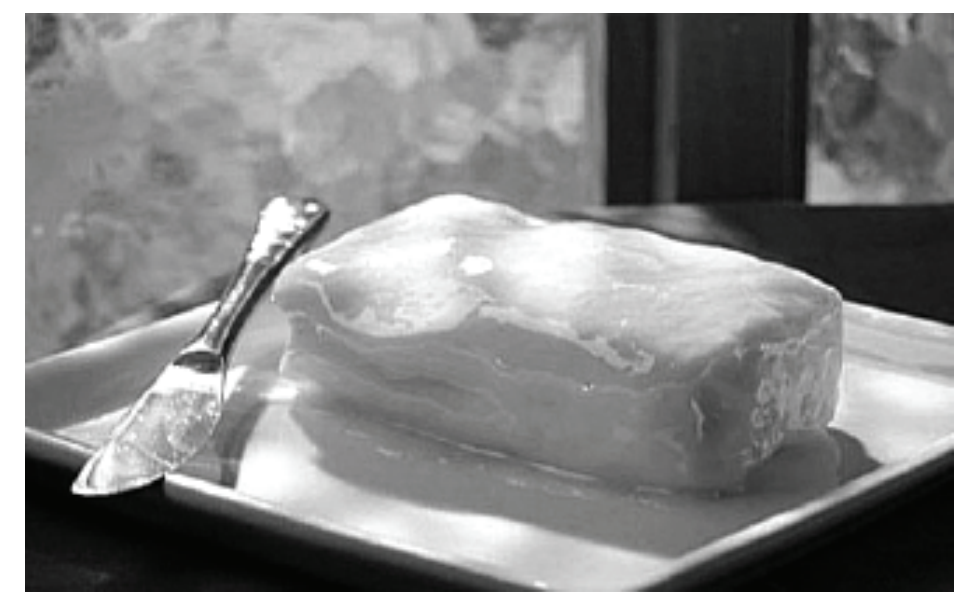

Mantequilla. Play.

En su ensayo "Memoria y melancolía”, el académico Domingo Hernández Sánchez propone acercarnos a la melancolía a partir de la relación de ésta con la memoria. Para él, la causa fundamental de la melancolía es el tiempo. El melancólico buscaría en el pasado la certidumbre de la que carece en el presente, particularmente en un presente -como el nuestro- que se define por la inseguridad y el cambio constante. Bajo esta mirada la relación del melancólico con el pasado se da a través de las cosas. Este encuentro cósico con el pasado traería, al mismo tiempo, alegría y angustia, ya que el pasado es irrecuperable, y las cosas rescatadas desde él, ya no son las mismas que conocimos antaño (2002: 134). En el nuevo contexto, estos elementos podrían ser llamados "antiguas cosas nuevas". Objetos extrañados, que podríamos relacionar hoy con la obsesión con el vintage. Una obsesión que no es nostálgica -ya que no se trata de volver al pasado-, sino melancólica, ya que el objetivo es traer la seguridad del pasado hacia nosotros a través de los objetos.
Hernández propone que aunque el arte es el que se hace cargo de estos objetos extrañados, pero que aún así la relación con el pasado, con el contexto propio de esos objetos, es muy problemática. Al ser traídos al presente, estos objetos pierden su contexto y en el proceso podemos perder con ellos los lazos habituales. Al hacer esto, los objetos van perdiendo su significado de utilidad, lo que los torna no sólo objetos extrañados, sino objetos extraños, amenazantes en su sin sentido: "Ahora la extrañeza de las cosas está en ellas mismas, su esencia es amenazante [...] donde más familiar se presenta el objeto es donde el efecto de extrañeza es más agudo si se lo separa de determinados modos de acercarse a él"(145).

La melancolía, que define de esta manera sus relaciones con las cosas, se origina como señalábamos más arriba, en la inseguridad que le produce al melancólico su propio tiempo, sus circunstancias. En su propia precariedad estos objetos serían la única posibilidad para el melancólico de relacionarse con algún sentido de orden, con la tranquilidad del pasado.

Jean Clair propone otra posible relación entre el sujeto melancólico y las cosas, una que tiene que ver con la fuga del sujeto desde su propio universo hacia uno que le resulta más seguro, al estar únicamente ocupado por objetos:

La conciencia melancólica es la que se aleja del mundo de lo vivo, de los humanos, para caer en el mundo de lo inerte, de las cosas. Al final, es una conciencia que, en su obsesión de la muerte, acaba por convertirse en cosa, por concebirse como objeto petrificado, pues la realidad inerte de los objetos se ha vuelto su único refugio, su único consuelo, su única alegría frente a la amenaza de la desaparición (1999: 94- 5).

Esta obsesión por los objetos, hace mucho sentido en el contexto de una sociedad de consumo y acumulación. Podemos suponer que la detención "cósica" de los realizadores permite crear para sus personajes, ciertos espacios de estabilidad, cierto refugio en el que descansar y perderse. Las cosas son anclas, son estables, permiten ser poseídas. Ante la incertidumbre del tiempo y las relaciones humanes, las cosas se vuelven cálidas.

Benjamín define al melancólico como "infiel", como alguien cuyo espíritu es "la fluctuación misma", en lo que se refiere a sus relaciones con las personas. Porque, cuando se trata de su relación con las cosas el melancólico se mantiene firme. Según Sontag, lo que Benjamin propone es que las profundas transacciones entre el melancólico y el mundo siempre ocurren con las cosas (y no con las personas), y que son transacciones genuinas, que revelan un significado. "Precisamente porque están obsesionados con la muerte, son los melancólicos los que mejor saben como leer el mundo. El mundo se abre ante el escrutinio del melancólico como ante nadie más. Cuanto más inertes las cosas, más potente e ingenioso puede ser el espíritu que las contempla" (2007: 128). Para Sontag, esta es la explicación del fetichismo del melancólico, de su gusto por las "cosas bellas o únicas", en sus palabras: "el temperamento melancólico es galvanizado por las pasiones que provocan objetos privilegiados"

\section{LA EXTRAÑEZA Y LA DESORIENTACIÓN}

Como decía más arriba, al instalar la cámara sobre los objetos y espacios cotidianos y detenerse en ellos es posible para el espectador crear ciertas conexiones de significación, 
a partir de su propio mundo interno. Se trata de volcar en esos cuerpos inertes, inmóviles, fotografiados el sentido que en el espectador provoca esta imagen. Con relación a esto, un fenómeno interesante que ocurre de manera constante en las "películas melancólicas" es la sensación de extrañeza que la detención en un lugar u objeto común puede provocar. En palabras de Jean Clair: "no obstante, ahí donde más familiar aparece el objeto, más corriente, más objetivo, es donde el efecto de extrañeza es más agudo [...] la extrañeza nace del alejamiento de la realidad que supone tal presentación" (66). Esta sensación se multiplica en los espacios en los que se mueven los personajes, esta extrañeza se expande también en los lugares en donde los personajes habitan, pero a los que saben que no pertenecen. Según Domenec esta relación ajena con los territorios, antes considerados propiamente humanos, es uno de los elementos constituyentes de la modernidad: "ya nada está en su sitio, ya no es posible rehacer la casa, los lugares, tradicionalmente de hábito, son también lugares de tránsito"(2002: 306).

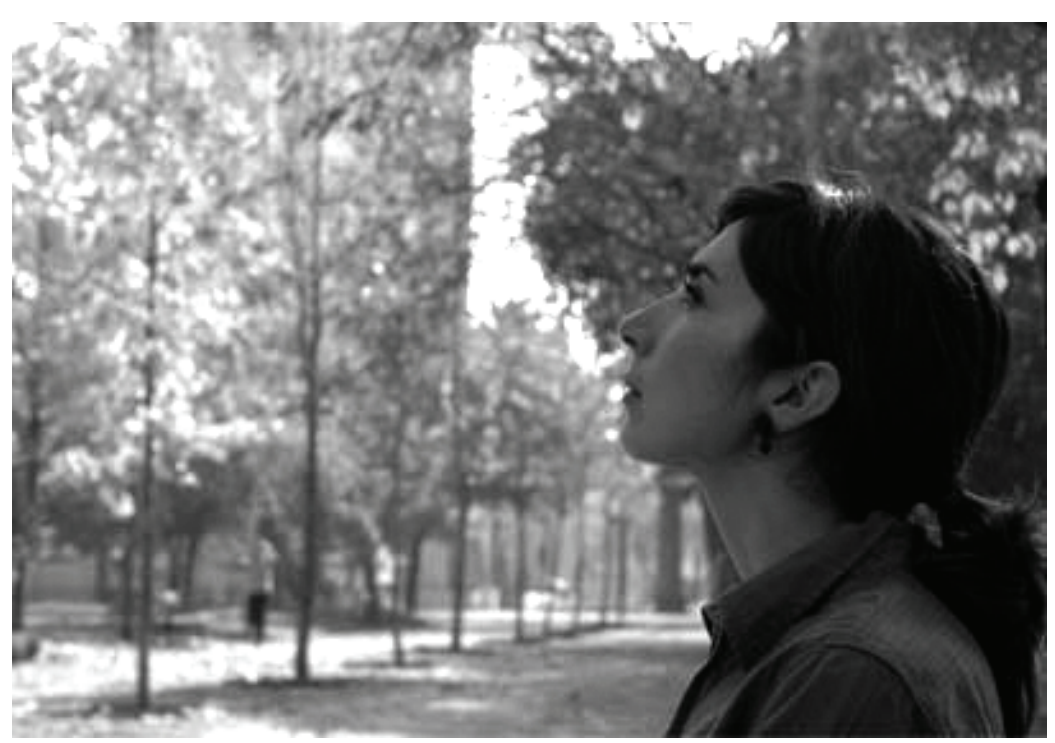

Rabia.

Al inicio señalaba como este joven cine chileno huía de la tradición que ha caracterizado parte importante de nuestro cine para ponerse bajo la influencia de otras corrientes. Volvemos al manejo del tiempo, pero ahora pensando en la lógica espacio temporal con la que se "ordenan" estas narraciones para ver cómo aquí también es desafiado el espectador y entregado a una sensación de desorientación frente a la historia que se le cuenta. En muchos casos no hay explicaciones de si las escenas están en orden cronológico o no, de si ocurren en un mismo espacio, de cuanto tiempo ha pasado entre una y otra. Todo para producir también en el espectador la confusión que invade a los personajes. Domenec Font nos da ciertas claves: "Lo que aparece en primera instancia en este eje de la descripción fílmica, es la condición del plano, su indecisión y con él un descentramiento de todo el relato. Por un lado es la duración y el ritmo perceptivo del plano que cambian produciendo fracciones sostenidas del tiempo. Y en paralelo, es la inmovilidad del plano que cesa de ser absoluta, y movimiento y reposo devienen dos términos relativos entre sí”(341-2).

El "cine melancólico" sería una reacción cinematográfica ante los duelos no resueltos y el vértigo de la modernización, propios de nuestra historia reciente. Este cine se definiría, entonces, por la emergencia de sus recursos formales e iría en la línea de lo que conocemos como cine moderno, cine crítico-expresivo o cine joven. Las características formales que le son propias tienen que ver con sus propuestas de guión, en los cuales se construye la trascendencia de la obra a partir de la expresión formal de historias que podrían ser consideradas argumentalmente como "mínimas", y el uso del lenguaje cinematográfico requiere de la participación activa del espectador para dotar de significación lo que ve. En este sentido, son claves el trabajo de montaje -tanto al interior del cuadro como en la edición- de planos secuencias, primeros planos y en términos de construcción narrativa que puede o no tener un orden cronológico en términos de tiempo y espacio, la manera en que se hace entrega de información al espectador. Una vez más la política dispone y las posibilidades del arte proponen salidas -o entradas- para aquel espectador inquieto que se atreve a aceptar esta invitación y a reconocer su historia compartida en las imágenes cinematográficas.

\section{REFERENCIAS}

Agamben, Giorgio. (2001). Estancias. La palabra y el fantasma en la cultura occidental Madrid: Pretextos.

Avelar, Idelber. (2000). Alegorías de la derrota: la ficción postdictatorial y el trabajo de duelo. Santiago: Cuarto Propio.

Bartra, Roger. (2001). Cultura y Melancolía. Las enfermedades del alma en la España del Siglo de Oro. Barcelona: Anagrama.

Clair, Jean. (1999). Malinconia. Madrid: Visor.

Del Sarto, Ana. (2001). Fuga melancólica. Aporías del "pensamiento crítico" chileno sobre la postdictadura. En "Pensar en /la postdictadura" Nelly Richard y Alberto Moreiras, editores. Santiago: Cuarto Propio.

Déotte, Martine. (2006). Desaparición y ausencia de duelo. En Nelly Richard (Ed.) Políticas y Estéticas de la Memoria. Santiago: Cuarto Propio.

Fernández Polanco, Aurora. (2005). Historia, montaje e imaginación: sobre imágenes y visibilidades. En Valeriano Bozal Fernández y Estrella de Diego Otero (Cord.) Imágenes de la violencia en el arte contemporáneo. Madrid: Machado Libros.

Figueroa Salas, Pamela. (2004). Antiutopía del Nuevo Chile: La experiencia cotidiana en la modernización neoliberal. Chile 1975-2004. Tesis para optar al grado de Licenciatura en Historia. Universidad de Chile.

Font, Domènec. (2002). Paisajes de la Modernidad. Cine europeo, 1960-1980. Barcelona: Paidós.

Hernández Sánchez, Domingo. (2002). La ironía estética. Estética romántica y arte moderno. Salamanca: Ediciones Universidad de Salamanca.

Kristeva, Julia. (1988). El lenguaje, ese desconocido. Madrid: Fundamentos.

-. (1991) Sol negro. Depresión y Melancolía Caracas: Monte Ávila Editores Latinoamericana. Levinson Brett. (2001). Post-transición y poética: el futuro del Chile actual. En Nelly Ri- 
chard y Alberto Moreiras (Ed.) Pensar en lla postdictadura. Santiago: Cuarto Propio. Lipovestky, Gilles. (2002). La era del vacío. Barcelona: Anagrama.

Martin, Adrian. (2008). ¿Qué es el cine moderno? Santiago: Uqbar.

Metz, Cristian. (2002). El cine moderno y la narratividad en "Ensayos sobre la significación en el cine (1964-1968). Vol. 1" Barcelona: Paidós.

Mitry, Jean. (2002). Estética y psicología del cine. Vol. 2 Las Formas. Madrid: Siglo XXI. Moulian, Tomás. (1997). Chile Actual. Anatomía de un mito. Santiago: Universidad Arcis/LOM -. (1998) El consumo me consume. Santiago: LOM.

Pasolini, Pier Paolo. (1971). Discurso sobre el plano-secuencia o el cine como semiología de la realidad. En Della Volpe y otros. Problemas del Nuevo Cine. Madrid: Alianza.

Pezella, Mario.(2004). Estética del cine. Madrid: A. Machado Libros.

Programa de Naciones Unidas para el Desarrollo, PNUD (2002) Desarrollo bumano en Chile. Nosotros los chilenos: un desafío cultural. Santiago.

Ossa, Carlos. (2005). Inmediatez y Frontera. En P. Oyarzún, N. Richard y C. Zaldívar (Ed.) Arte y Política Santiago: Consejo Nacional de la Cultura y las Artes, Universidad Arcis, Universidad de Chile.

Ramos, Carmen Gloria y Simonsen, Elizabeth. (1999). "Santiago, la ciudad de la angustia": Santiago. Revista Qué Pasa 1470: 16.

Richard, Nelly. (2001). "Las marcas del destrozo y su reconjugación en plural". En Nelly Richard y Alberto Moreiras (Ed.) Pensar en /la postdictadura. Santiago: Cuarto Propio. -. (1981). Residuos y Metáforas. Santiago: Cuarto Propio.

Ruiz, Carlos. (2006). Democracia, consenso y memoria: una reflexión sobre la experiencia chilena. En Nelly Richard (Ed.) Políticas y Estéticas de la Memoria. Santiago: Cuarto Propio.

Sontag, Susan. (2007). Bajo el signo de Saturno. Buenos Aires: Debolsillo

Subercaseux, Benjamín. (1939). Apuntes para una psicología del chileno. Santiago: Zig-Zag.

Recepción: lunes 7 de septiembre de 2009 Aceptación: martes 5 de enero de 2010 